2nd International Conference Global Ethics -Key of Sustainability (GEKoS) | May 14, 2021 | Bucharest, Romania

\title{
Can Online Learning Lead to Better Results of Knowledge Acquisition?
}

\author{
Maria-Mădălina TABARCIA, Ionel-Sorinel VASILCA, Madlena NEN, \\ Mihail BĂRĂNESCU
}

https://doi.org/10.18662/lumproc/gekos2021/19

How to cite: Tabarcia, M.-M., Vasilica, I.-S., Nen, M., \& Bărănescu, M. (2021). Can Online Learning Lead to Better Results of Knowledge Acquisition?. In A. Grigorescu \& V. Radu (vol. ed.), Lumen Proceedings: Vol. 15. 2nd International Conference Global Ethics - Key of Sustainability (GEKoS) (pp. 218-224). Iasi, Romania: LUMEN Publishing House. https://doi.org/10.18662/lumproc/gekos2021/19 


\title{
Can Online Learning Lead to Better Results of Knowledge Acquisition?
}

\author{
Maria-Mădălina TABARCIA¹, Ionel-Sorinel VASILCA², \\ Madlena NEN33, Mihail BĂRĂNESCU4
}

\begin{abstract}
Implementing a performant knowledge management system in military institutions involves emphasizing the role of the organizational dimension that promotes learning, increasing the quality of employees' work and consolidating managers in these institutions as leaders who encourage learning at all levels. The objectives of knowledge acquisition must be defined in such a way as to improve performance and support the trust of the beneficiary of the public service provided. The development of organizational culture within the institution allows people to adopt new values, attitudes and behaviors. Investing in an efficient knowledge management system involves the development of training and education programs that contribute to improving the skills of employees and knowledge sharing both vertically and horizontally, in order to provide quality public service and create value within the community. Knowledge management can be implemented more efficiently and beneficially in the context of the increasing use of technology in educational activities. Thus, integration of e-learning in knowledge management systems allows the removal of space and time barriers from learning. The question is whether current e-learning systems meet the requirements of knowledge management and provide results comparable to those obtained through traditional learning.
\end{abstract}

Keywords: knowledge management, e-learning, online learning, offline learning, F2F learning.

\footnotetext{
${ }^{1}$ Bucharest University of Economic Studies, Romania, ulmeanumaria20@stud.ase.ro

${ }^{2}$ Bucharest University of Economic Studies, Romania, sorinvasilca@gmail.com

${ }^{3}$ Bucharest Military Technical Academy „Ferdinand I”, Romania, madlenanen@yahoo.com

${ }^{4}$ Bucharest University of Economic Studies, Romania, baranescumihail@yahoo.com
} 
Maria-Mădălina TABARCIA et al. | Lumen Proceedings 15 | GEKoS 2021

\section{Introduction}

The human capital theory explains how individuals or people develop the knowledge, skills and abilities that individuals have in completing their work or contribute to the organization and how these individuals make choices to invest their energy, thoughts and money in increasing knowledge, skills and knowledge and health. Which becomes human capital for him to increase his contribution to the organization (Rusmingsih et al., 2021).

It is necessary for public administration institutions to support the development of human capital that creates public value. Bureaucracies remain a predominant form of organization today especially in public administration, military organizations, and large corporations (Greenwood \& Lawrence, 2005; Lounsbury \& Carberry, 2005). This paper investigates the relationship between online and offline practices in terms of staff training when the organizational environment is bureaucratic, as is the Special Telecommunications Service, an organization with a military structure that is part of the national defence system. The research question refers to investigate the similarities, in terms of benefits, between online and offline practices, especially when we talk about integrating the staff training process into the knowledge management system and how this can contribute to the transformation of the bureaucratic organization. The study is based on the analysis of literature in the field of online and offline training practices within military organizations.

\section{Problem Statement}

\subsection{Knowledge-based organizations}

A knowledge-based organization is a company that has adapted its organizational structure and processes to facilitate the creation of an environment conducive to the acquisition, dissemination and use of knowledge for the supply of high value-added services (Castells, 1998; Grant, 1996; Hess \& Bacigalupo, 2010; Nonaka, 1994; 10; Starbuck, 1992). Human resource training, knowledge management, and performance are considered essential for any organization that wants to achieve knowledge management $(\mathrm{KM})$ goals and improve its performance.

A decisive role is how group cohesion can be increased, cooperation and communication between employees (organizational structure, leadership style, organizational culture, motivation and reward, etc.) and not the instruments through which they can be collected. Although the ways of 
defining the concept of "knowledge-based organizations" have evolved significantly in recent years, opinions on their existence are still divided.

Thus, some authors consider that they are "companies of the future" (Broughton, 2010), while others argue that any organization is based on knowledge as long as its work involves the use of the experience, skills and skills of its employees (Grey \& Sturdy, 2009).

\subsection{Employee training and development}

Each organization has its own specifics, but the employees are the ones who make things possible. The key role is played by the organization's management, namely to attract, train and retain the right employees, who through their work and dedication to contribute to the performance and sustainable development of the organization (Morosan-Danila et al., 2020).

On the one hand, employee training involves programs that allow employees to learn precise skills or knowledge. On the other hand, development programs involve a broader employee growth plan. The first aims to increase the immediate performance, the others refer to the increase of the future performance of the organization.

Training must change the attitude, skills and behavior of both new and old employees in the organization, as both categories of employees need to work more efficiently.

Training is a short-term learning process in which performing employees acquire knowledge and skills to improve their productivity. (Sasongko et al., 2020).

Last but not least, the training and work environment, the possibility of self-development and self-expression are elements of attracting talents (Grigorescu et al., 2020).

All forms of training must focus on meeting the organization's objectives and future skills needed in the workplace. At the same time, the training must be delivered in an innovative way.

Public administration should identify a pathway for sustainability investing in people, organization andpolicies in order to drive change withinpublic organizations. New public managers should behave and act as ethical and transformational leaders (Romanelli, 2020).

Knowledge management is more than training and development, because neither training nor development is enough and everyone has their limits. Development starts from the wishes of the individual, and training involves the needs of the organization, even if the latter may also contain individual development. In a world of uncertainty, in which technology, competition or crisis, such as the Covid-19 pandemic, make the 
Maria-Mădălina TABARCIA et al. | Lumen Proceedings 15 | GEKoS 2021

environment more turbulent, the need for knowledge becomes imperative. Under these circumstances, training may often become less effective. However, if the organization focuses on employee development, they may accept uncertainty if they are properly guided to those types of knowledge that will count for the future functioning of the organization. Otherwise, if they are sent to classes and do not practice what they learned when they return to their organizations, employees can become frustrated and disappointed. This result can be a substantial waste of resources and time.

\section{Discussion}

The biggest benefit of face-to-face learning is the ability to collaborate, discuss, and practice, under the guidance of a dedicated trainer. Being part of a group and being corrected on the spot are powerful learning tools. Most of all, face-to-face learning is a social event.

One of the main advantages of distance learning is the increased level of flexibility and the fact that a large number of employees can be trained at the same time. It also offers access to a wide range of online resources. These tools mean that employees can experience a sense of community and teaching support similar to those attending face-to-face courses. In this case, it is essential for employees to be able to interact with a community of employees who study the same course material.

Within military organization, there are two main forms of training: the initiation part, the mandatory training which starts after the candidates pass the admission tests, and the compliance training, which extends throughout the entire career. Both training programs are important, but the latter has the greatest impact on the provision of quality public service.

The main purpose of the initial training is to reduce their need to ask other staff for advice or information, by increasing their independence and diminishing the chance that they would make mistakes that could cost in prestige, citizens' confidence or lawsuits.

For veteran staff, training programs help them to become continually more competent at what they do and increase their knowledge of the field by introducing them to the latest regulations, mistakes made, and good practices learned and expose them to new ideas which ultimately may improve their effectiveness. Another purpose of compliance training is to keep them from becoming bored and stale, and to maintain interest in and enthusiasm for their work.

There are learning centres dedicated to the training at a national level, and there is a training department consisting of staff members with the 
right background and, completely dedicated to the professional training activities. Considering that the employees work countrywide, to ensure a continuous flow of professional training, a mix of courses is used, both online and offline.

In short, there is a constant concern with providing continuing education programs for all staff, being aware that this leads to increasing organizational efficiency and keeps it growing.

As digital learning is carried out by an individual rather than a group and therefore presents an opportunity for personalization, a good option could be online blended learning. Each employee can use it when they need it and can adapt to the way individuals react. Online items mean that they can be easily reused and revised, not to mention the benefit of easy updates.

\section{Conclusions}

Sustainable implementation of knowledge management within a military organization is advancing relying on investing in training and developing the quality of human capital. In particular, the promotion of the most efficient ways of training employees ensures the development of an organizational culture oriented to knowledge sharing and efficient behaviour in the work environments.

To implement an efficient knowledge management system, the Romanian Telecommunication Service must be constantly concerned with finding and using the perfect balance of training forms, to preserve the knowledge-based organizational culture and to have competent employees willing to share their knowledge.

Compliance training will continue to be done mainly online or where possible, through a mix of online and offline, while the initial training of new employees will traditionally be done in specialized training centres. Thus, the future approach will take into account the development of training in the form of a F2F mix and online, to benefit from the advantages of each form of training.

A practical benefit of this paper is the fact that it helps to reach organizational purposes (through a better understanding of the elements which are involved).

This paper has some limitations, being presented empirical research. Additional research is needed to analyze the answer to the question: "What is the best option for my organization: online training or offline training?", and which option is better. In order to ensure a high degree of completeness 
Maria-Mădălina TABARCIA et al. | Lumen Proceedings 15 | GEKoS 2021

and depth in knowledge management practices, it is necessary to address all the critical factors, which could be the subject of future research.

Online training of human resources could relate to better assessment and this can substantiate the approach to continue and intensify the training of this category of employees through online programs. Future research could also examine the conditions and processes by which online training can influence the outcomes of knowledge and skills in terms of workplace performance.

\section{References}

Broughton, V. (2010). The fall and rise of knowledge organization: new dimensions of subject description and retrieval. Aslib Proceedings: New Information Perspectives, 62(4), 349-354. https://doi.org/10.1108/00012531011074618

Castells, M. (1998). La société enréseaux - t. 1: L'ère de l'information [The network company (vol 1): The information age]. Fayard.

Grant, R. M. (1996). Toward a knowledge - based theory of the firm. Strategic Management Journal, 17(1), 109 - 122. http://dx.doi.org/10.1002/smj.4250171110

Greenwood, R., \& Lawrence, T. B. (2005). The iron cage in the information age: The legacy and relevance of Max Weber for organization studies. Editorial. Organization Studies, 26(4),493-499. https://doi.org/10.1177\%2F0170840605051465

Grey, C., \& Sturdy, A. (2009) Historicising knowledge - intensive organizations: The case of Bletchley Park. Management \& Organizational History, 4(2), 131 150. https://doi.org/10.1177\%2F1744935909102905

Grigorescu, A., Lincaru, C., \& Pîrciog, S. (2020). Ethic Leadership Trigger for Talents. In A. Grigorescu \& V. Radu (vol. ed.), Lumen Proceedings: Vol. 11. 1st International Conference Global Ethics - Key of Sustainability (GEKoS) (pp. 3244). Iasi, Romania: LUMEN Publishing House. https://doi.org/10.18662/lumproc/gekos2020/05

Hess, J. D., \& Bacigalupo, A. C. (2010). The emotionally intelligent leader, the dynamics of knowledge - based organizations and the role of emotional intelligence in organizational development. On the Horizon, 18(3), 222 - 229. https://doi.org/10.1108/10748121011072672 
Maria-Mădălina TABARCIA et al.| Lumen Proceedings 15 | GEKoS 2021

Lounsbury, M., \& Carberry, E. J. (2005). From king to court jester? Weber'sfall from grace in organizationaltheory. Organization Studies, 26(4), 501-525. https://doi.org/10.1177/0170840605051486

Morosan-Danila, L., Nastase, C.-E., \& Grigoras-Ichim, C.-E. (2020). The Link Between Employees' Motivation With Organization's Performance. In A. Grigorescu V. Radu (vol. ed.), Lumen Proceedings: Vol. 11. 1st International Conference Global Ethics -Key of Sustainability (GEKoS) (pp. 264-272). Iasi, Romania: LUMEN Publishing House. https://doi.org/10.18662/lumproc/gekos2020/27

Nonaka, I. (1994). A dynamic theory of organizational knowledge creation. Organization Science, 5(1), 14 - 37. https://doi.org/10.1287/orsc.5.1.14

Romanelli, M. (2020). Driving Sustainable Public Administration. In A. Grigorescu \& V. Radu (vol. ed.), Lumen Proceedings: Vol. 11. 1 st International Conference Global Ethics -Key of Sustainability (GEKoS) (pp. 24-31). Iasi, Romania: LUMEN Publishing House. https://doi.org/10.18662/lumproc/gekos2020/04

Rusmingsih, D., Widarni, E. L., \& and Bawono, S. (2021). Human Psychological Factors in the Success of Human Capital Investment in Driving Financial Performance, Case Study of the Hotel Industry in Indonesia and Malaysia. HOLISTICA - Journal of Business and Public Administration, 12, (1), 69-75. https://doi.org/10.2478/hjbpa-2021-0007

Sasongko, B., Widarni, E. L., \& Bawono, S. (2020). Training Analysis and Locus of Control on Self Efficacy and Work Ability of Employees. HOLISTICA Journal of Business and Public Administration, 11(1), 29-50.

https://doi.org/10.2478/hjbpa-2020-0003

Starbuck, W. H. (1992). Learning by knowledge - intensive firms. Journal of Management Studies, 29(6), 713 - 740. https://doi.org/10.1111/j.14676486.1992.tb00686.x 